\title{
Interventional Radiology Preparedness in the Time of the COVID-19 Pandemic: Is there a Gold Standard?
}

\author{
Bien-Soo $\operatorname{Tan}^{1}$ (D) $\cdot$ Kiang-Hiong Tay ${ }^{1}$
}

Received: 18 April 2020/Accepted: 28 April 2020/Published online: 20 May 2020

(C) Springer Science+Business Media, LLC, part of Springer Nature and the Cardiovascular and Interventional Radiological Society of Europe (CIRSE) 2020

The Coronavirus disease 2019 (COVID-19) pandemic has continued to worsen and has reached a scale that has not been seen since the Spanish Flu pandemic over a hundred years ago in 1918 [1]. As of 15 Apr 2020, there are more than 1.9 million cases with more than 125000 deaths worldwide [2]. Health care worker (HCW) infections resulting from caring and treating COVID-19 patients have also occurred in large numbers in some countries and many have perished [3, 4]. Protecting patients and HCWs from getting infected while maintaining high-quality care are key considerations for any interventional radiology (IR) service during this pandemic.

Since the outbreak, several manuscripts, guidelines and checklists on IR preparedness and COVID-19 have been published [5-18]. Many IR webinars on COVID-19 have also been broadcasted. This rapid sharing of information, experiences and best practices is unprecedented and bodes well for our specialty. It has undoubtedly helped many IR services throughout the world to prepare and deal with the COVID-19 pandemic.

The principles of managing a highly infectious disease with significant morbidity and mortality like COVID-19 are universal. Strict adherence to hand hygiene practices, proper use of appropriate personal protective equipment (PPE) and implementation of team segregation and social distancing are critical in preventing intra-hospital transmission and cross-infection of patients and HCWs. Other

Bien-Soo Tan

tan.bien.soo@singhealth.com.sg

1 Department of Vascular and Interventional Radiology, Singapore General Hospital, SingHealth Duke-NUS Academic Medical Centre, 20 College Road, Academia Level 4, 169856 Singapore, Singapore strategies to minimise cross-transmission include segregating patients of different infection risks, identifying and isolating COVID-19 patients early and minimising their movement, and when necessary, performing procedures for COVID-19 patients either at the bedside or in pre-designated interventional suites. It is therefore important to have detailed, well-rehearsed IR protocols for dealing with COVID-19 patients, as described by many of these publications. While these principles are universal, they may not be uniformly implementable due to local constraints like PPE supply or the extent of the COVID-19 load within the institution. Hence each IR service may have to modify their protocols to cater to their own unique circumstances.

The N95/FFP 2/3 mask is generally recommended when coming in close contact with COVID-19 patients. There are reports of inadvertent exposure of HCWs wearing only surgical masks to undiagnosed COVID-19 patients, with no transmission to the HCWs [19]. This suggests that surgical masks may confer adequate protection and offers reassurance to IR services where there are shortages of N95/FFP $2 / 3$ masks. There are also controversies with regards to the use of powered air-purifying respirators (PAPR) when performing aerosol-generating procedures (AGP) in COVID-19 patients. Existing WHO guidelines for performing AGPs in patients with airborne infections are N95/ FFP 2 mask and eye protection (goggles or face shield) [20], but many institutions have adopted PAPR when performing AGPs in COVID-19 patients. This enhanced measure is not evidence-based but is understandable in the light of the knowledge gap concerning COVID-19. PAPRs are also not widely available and would not be universally deployed in every IR service.

Depending on the extent of local community spread of COVID-19, it is quite possible that HCWs can contract the 
infection in the community rather than in the hospital. Coupled with the possibility of pre-symptomatic spread $[21,22]$, it is prudent for all HCWs to don surgical masks while at work to minimise the risk of $\mathrm{HCW}$ to $\mathrm{HCW}$ transmission. Social distancing measures like minimising face to face meetings and sitting alone or widely apart during meals will also go a long way to prevent crosstransmission among HCWs.

Ultimately, it will be adoption of the whole slew of measures by everyone in the team that will ensure the protection of members of the IR service and their patients.

Funding This study was not supported by any funding.

\section{Compliance with Ethical Standards}

Conflict of interest The authors declare that they have no conflict of interest.

Human Rights This article does not contain any studies with human participants performed by any of the authors.

Informed Consent For this type of study, informed consent is not required.

Consent for Publication For this type of study, consent for publication is not required.

\section{References}

1. Taubenberger JK, Morens DM. 1918 Influenza: the mother of all pandemics. Emerg Infect Dis. 2006;12(1):15-22.

2. Coronavirus COVID-19 Global Cases by the Center for Systems Science and Engineering (CSSE) at Johns Hopkins University (JHU), https://coronavirus.jhu.edu/map.html, accessed on 15 April 2020.

3. World Health Organisiation Coronavirus disease 2019 (COVID19) Situation Report - 82, Subject in focus : infections in health care workers. Available from: https://www.who.int/docs/defaultsource/coronaviruse/situation-reports/20200411-sitrep-82-covid19.pdf?sfvrsn=74a5d15 2

4. Liu M, He P, Liu HG, Wang XJ, Li FJ, Chen S, Lin J, Chen P, Liu JH, Li CH. Clinical characteristics of 30 medical workers infected with new coronavirus pneumonia. Zhonghua Jie $\mathrm{He} \mathrm{He}$ Hu Xi Za Zhi. 2020;43(3):209-14.

5. Zhuang KD, Tan BS, Tan BH, Too CW, Tay KH. Old Threat, New enemy : is your interventional radiology service ready for the coronavirus disease. Cardiovasc Intervent Radiol. 2020. https://doi.org/10.1007/s00270-020-02440-6.

6. Cheng LTE, Chan LP, Tan BH, Chen RC, Tay KH, Ling ML, Tan BS. Déjà Vu or Jamais Vu? How the severe acute respiratory syndrome experience influenced a singapore radiology department's response to the Coronavirus Disease (COVID-19) epidemic. Am J Roentgenol. 2020;215(Feb):1-5, Epub 5 Mar 2020. Available from: https://www.ajronline.org/doi/full/10.2214/AJR. 20.22927

7. Pua $\mathrm{U}$, Wong $\mathrm{D}$. What is needed to make interventional radiology ready for COVID-19? lessons from SARS-CoV epidemic. Korean J Radiol. 2020. Epub 13 Mar 2020. Available from: https:// www.kjronline.org/DOIx.php?id=10.3348/kjr.2020.0163
8. Mossa-Basha M, Meltzer CC, Kim DC, Tuite MJ, Kolli KP, Tan BS. Radiology department preparedness for COVID-19: radiology scientific expert panel. Radiology. 2020. https://doi.org/10. 1148/radiol.2020200988.

9. PE Chandy, MU Nasir,S Srinivasan, D Klass, S Nicolau, SB Babu: Interventional radiology and COVID-19: evidence-based measures to limit transmission. Diagn Interv Radiol 2020; Epub 27 Mar 2020. Available from: https://www.dirjournal.org/en/ interventional-radiology-and-covid-19-evidence-based-measuresto-limit-transmission-167911

10. Tan BS, Tay KH, Tan BH, Chung JW, Gangi A, Binkert C, Morgan R, Pereira P, Adam A, Holden A: Joint CIRSE-APSCVIR Checklist for preparing your IR service for COVID-19. Available from: https://www.cirse.org/wp-content/uploads/2020/ 04/CIRSE_APSCVIR_COVID19_Checklist.pdf

11. Goh Y, Chua W, Lee JKT, Ang BWL, Liang CR, Tan CA, Choong DAW, Hoon HX, Ong MKL, Quek ST. Operational strategies to prevent coronavirus disease 2019 (COVID-19) spread in radiology: experience from a Singapore radiology department after severe acute respiratory syndrome. J Am Coll Radiol. 2019. https://doi.org/10.1016/j.jacr.2020.03.027.

12. HD Zhu, CH Zeng, J Lu, GJ Teng. COVID-19: what should interventional radiologists know and what can they do? J Vasc Intervent Radiol 2020, Epub 9 Apr 2020. Available from: https:// www.sciencedirect.com/science/article/pii/S1051044320303365

13. A Gogna, S Punamiya, A Gopinathan, F Irani, LHW Toh, LHW Cheong, S Babu, B Wee, PYT Goh, BP Tan, K Damodharan, N Venkatanarasimha, SJM Chan, S Chandramohan, CW Too, R Chung, SJ Ong, AGS Tan, BS Tan, KH Tay. Preparing IR service for the COVID-19 pandemic-the Singapore Experience. J Vasc Intervent Radiol 2020, Epub 9 Apr 2020. Available from: https:// www.sciencedirect.com/science/article/pii/S1051044320303353

14. Ierardi AM, Wood BJ, Gaudino C, Angileri SA, Jones EC, Hausegger K, Carrafielloet G. How to handle a COVID-19 patient in the angiographic suite. Cardiovasc Intervent Radiol. 2020. https://doi.org/10.1007/s00270-020-02476-8.

15. IYY Tsou CJY Liew BP Tan H Chou SBS Wong KSH Loke RCW Quah AGS Tan KH Tay Planning and coordination of the radiological response to the coronavirus disease 2019 (COVID19) pandemic: the Singapore experience Clin Radiol 2020, Epub 11 Apr 2020. Available from: https://doi.org/10.1016/j.crad.2020. 03.028

16. Cardiovascular and Interventional Radiology Society of Europe COVID-19 Resource Centre. Available from: https://www.cirse. org/education/covid-19-resource-centre/

17. Society of Interventional Radiology COVID-19 preparedness Tool kit. Available from: https://www.sirweb.org/practiceresources/toolkits/covid-19-toolkit/

18. CW Too, D Wen, A Patel, ASA Rahman, J Liu, S Leong, A Gogna, RHG Lo, S Tashi, KA Lee, P Kumar, SA Lie, YC Tay, CL Lai, ML Ling, BS Tan, KH Tay. Interventional radiology procedures for COVID-19 patients: how we do it. Cardiovasc Intervent Radiol 2020 (in press)

19. K Ng, BH Poon, THK Puar, JLS Quah, WJ Loh, YJ Wong, TY Tan, J Raghuram. COVID-19 and the risk to health care workers: a case report. Ann Intern Med. 2020. Epub 16 Mar 2020. Available from: https://www.ncbi.nlm.nih.gov/pmc/articles/ PMC7081171/

20. WHO Guidelines for Infection prevention and control of epidemic and pandemic-prone acute respiratory infections in health care. Available from: https://apps.who.int/iris/bitstream/handle/ 10665/112656/9789241507134_eng.pdf;jsessionid=BE25F8EAA 4F631126E78390906 050313? sequence $=1$

21. Tong Z-D, Tang A, Li K-F, Li P, Wang H-L, Yi J-P, Zhang Y-L, Yan J-B. Potential presymptomatic transmission of SARS-CoV- 
2, Zhejiang Province, China. Emerg Infect Dis. 2020. https://doi. org/10.3201/eid2605.200198.

22. Wei WE, Li Z, Chiew CJ, Yong SE, Toh MP, Lee VJ. Presymptomatic Transmission of SARS-CoV-2-Singapore, January 23-March 16, 2020. MMWR Morb Mortal Wkly Rep
2020;69:411-415. Epub 1 Apr 2020. Available from: https://dx. doi.org/10.15585/mmwr.mm6914e1

Publisher's Note Springer Nature remains neutral with regard to jurisdictional claims in published maps and institutional affiliations. 